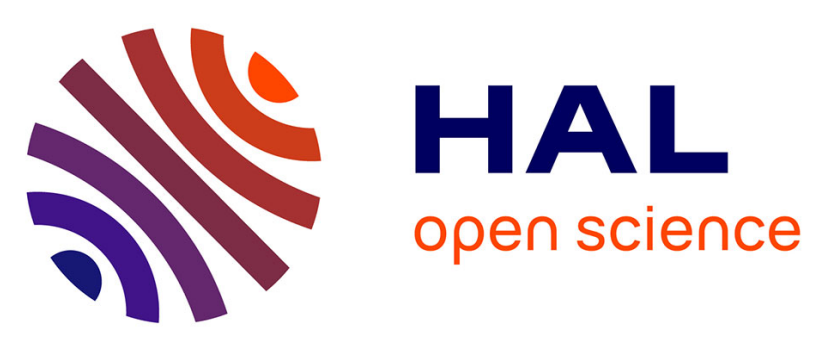

\title{
OSCAR-Na: A New Code for Simulating Corrosion Product Contamination in SFR
}

J.B. Génin, L. Brissonneau, T. Gilardi

\section{To cite this version:}

J.B. Génin, L. Brissonneau, T. Gilardi. OSCAR-Na: A New Code for Simulating Corrosion Product Contamination in SFR. Metallurgical and Materials Transactions E, 2016, 3 (4), pp.291-298. 10.1007/s40553-016-0094-9 . cea-02381347

\section{HAL Id: cea-02381347 https://hal-cea.archives-ouvertes.fr/cea-02381347}

Submitted on 26 Nov 2019

HAL is a multi-disciplinary open access archive for the deposit and dissemination of scientific research documents, whether they are published or not. The documents may come from teaching and research institutions in France or abroad, or from public or private research centers.
L'archive ouverte pluridisciplinaire HAL, est destinée au dépôt et à la diffusion de documents scientifiques de niveau recherche, publiés ou non, émanant des établissements d'enseignement et de recherche français ou étrangers, des laboratoires publics ou privés. 


\author{
J-B. Génin ${ }^{1}$, L. Brissonneau ${ }^{2}$, T. Gilardi ${ }^{2}$ \\ ${ }^{1}$ CEA, DEN Cadarache, DTN/SMTA/LMTR, F13108, Saint-Paul-Lez-Durance, France \\ ${ }^{2}$ CEA, DEN Cadarache, DTN/SMTA/LIPC, F13108, Saint-Paul-Lez-Durance, France
}

\begin{abstract}
A code named OSCAR-Na has been developed to calculate the mass transfer of corrosion products in the primary circuit of sodium fast reactors (SFR). It is based on a solution/precipitation model, including diffusion in the steel (enhanced under irradiation), diffusion through the sodium boundary layer, equilibrium concentration of each element and velocity of the interface (bulk corrosion or deposition). The code uses a numerical method for solving the diffusion equation in the steel and the complete mass balance in sodium for all elements. Corrosion and deposition rates are mainly determined by the iron equilibrium concentration in sodium and its oxygen enhanced dissolution rate. All parameters of the model have been assessed from a literature review, but iron solubility had to be adjusted. A simplified primary system description of PHENIX French SFR was able to assess the correct amounts and profiles of contamination on heat exchanger surfaces for the main radionuclides.
\end{abstract}

\title{
INTRODUCTION
}

In Sodium Fast Reactors (SFR), mass transfer occurs due to the difference of solubility in the sodium of the steel elements at the hot parts and the cold parts of the primary vessel. Corrosion (element release in the sodium) takes place at the hot parts (773K or higher), namely the upper parts of the core and of the intermediate heat exchangers (IHX), the elements are transported in the sodium and deposited in the cold parts (when their concentration exceeds their solubility limit), the lower part of the IHX, the primary pumps (PP), and the lower part of the core. As the claddings are activated under the neutron flux, one part of the release elements are radionuclides, the deposition of which leads to the contamination of the components (IHX, PP). The main radioactive contaminants are ${ }^{54} \mathrm{Mn}$ and ${ }^{60} \mathrm{Co}$.

It is important to understand the consequence of the operating parameters (temperature, oxygen content in $\mathrm{Na}$, $\mathrm{Na}$ velocity) on the corrosion of the claddings and the global mass transfer. The assessment of the radioactive contamination of reactor primary circuits is necessary to address important challenges while operating, designing or decommissioning a nuclear power plant, such as decreasing personnel exposure to radiation during maintenance (reparation) or dismantling operations on macrocomponents, as well as limiting the activity of wastes and effluents produced during these operations.

Therefore the computer code OSCAR-Na has been developed for SFR contamination and mass transfer assessment. It is based on the OSCAR code [1], a mass transfer code up to now dedicated to Pressurized Water Rectors (PWR). The OSCAR code is a modular code which can easily integrate new models.

The selected model for mass transfer in SFR primary circuit assumes that transfer between steel and sodium is primarily by solution and precipitation (rather than, for example, by particle detachment and particle deposition) and thus, it can be deduced from mass transfer theory. This model has been described in detail by Polley and Skyrme [2] Erreur ! Source du renvoi introuvable..

This paper describes how this model is implemented in the OSCAR-Na code, taking into account a complete mass balance around the circuit for each nuclide. After a description of the 
solution/precipitation model and a reminder of the analysis made by Polley and Skyrme, the implementation of the model in OSCAR-Na is detailed and the values chosen for the key parameters are defined. Finally, first results are discussed.

\section{THE SOLUTION/PRECIPITATION MODEL}

Theory

As described by Polley and Skyrme [2], mass transfer of each element of interest between sodium and steel (whatever release or deposition is considered) may be characterized by an expression derived by equating three relationships for the mass flux 1) across the liquid laminar boundary layer, 2) for absorption and desorption at the steel/sodium interface and 3) for diffusion in the steel. These are respectively:

$$
\begin{gathered}
\Phi=k \cdot\left(C_{i}{ }^{\prime}-C^{\prime}\right) \\
\Phi=k_{d} \cdot C_{i}-k_{a} \cdot C_{i}{ }^{\prime} \\
\Phi=D \cdot\left(\frac{\partial C}{\partial x}\right)_{x=0}+u \cdot C_{i}
\end{gathered}
$$

Where $\mathrm{C}$ and $\mathrm{C}^{\prime}$ are the nuclide concentration in the steel and bulk sodium, respectively (the subscript $i$ indicating interfacial values at $\mathrm{x}=0$ ), $\mathrm{k}$ is the mass transfer coefficient for diffusion through the laminar boundary layer, $\mathrm{k}_{\mathrm{a}}$ and $\mathrm{k}_{\mathrm{d}}$ the "absorption" and "desorption" mass transfer coefficients, respectively (rates of transfer from the sodium to the interface and vice versa), D the diffusion coefficient in the steel, $x$ the depth from the surface into the steel, and $u$ the velocity of the moving sodium/steel interface ( $\mathrm{u}>0$ in case of bulk corrosion, $\mathrm{u}<0$ in case of bulk deposition). The mass flux is positive in case of release into the sodium, and negative in case of deposition.

In eq. (2), first order rate theory is assumed, i.e. mass fluxes are supposed to be linearly proportional to concentrations: $\mathrm{k}_{\mathrm{d}}$ is the rate constant for the release from the steel surface in the sodium and $\mathrm{k}_{\mathrm{a}}$ the rate constant for the reverse reaction.

Eliminating $\mathrm{C}_{\mathrm{i}}$ ' from eqs. (1) and (2) yields:

$\Phi=K \cdot\left(\frac{C_{i}}{\beta}-C^{\prime}\right)$

Where $K=k \cdot k_{a} /\left(k+k_{a}\right)$ is the effective mass transfer coefficient and $\beta=k_{a} / k_{d}$ the dimensionless chemical partition coefficient. The physical significance of $\beta$ may be understood using eq. (2). At chemical equilibrium, $\Phi$ is zero and hence $\beta=\mathrm{C}_{\mathrm{i}} / \mathrm{C}^{\prime}$ eq, where $\mathrm{C}^{\prime}$ éq is the concentration in the sodium in equilibrium with a solid presenting the concentration $C_{i}$ at the surface. Thus, $\beta$ is small or large for elements which are highly soluble or insoluble in sodium, respectively.

So the model is defined by four main parameters: K, D, $\beta$ (for each element), and $\mathrm{u}$. Knowing the concentration $C^{\prime}$ in the sodium, the concentration profile in the steel (and hence $C_{i}$ ) can be calculated by solving the relevant diffusion equation:

$\frac{\partial C}{\partial t}=D \cdot\left(\frac{\partial^{2} C}{\partial x^{2}}\right)+u \cdot \frac{\partial C}{\partial x}-\lambda \cdot C+R$ 
Where $\lambda$ is the decay constant due to radioactive decay and neutron capture, and $R$ is the rate of production by neutron activation (if appropriate for the element and the surface considered).

The steel is assumed to be of infinite thickness and the boundary condition at the interface is derived from equating (3) and (4):

$$
D \cdot\left(\frac{\partial C}{\partial x}\right)_{x=0}+u \cdot C_{i}=K \cdot\left(\frac{C_{i}}{\beta}-C^{\prime}\right)
$$

The mass flux between steel and sodium is then obtained by substituting for $C_{i}$ in equation (4).

Analysis section.

Some conclusions of the analysis proposed by Polley and Skyrme [2] are reminded in this

Release from surfaces submitted to bulk corrosion $(u>0)$.

The release is said to be stoichiometric when the concentration in the steel is uniform. Hence $\Phi=$ C.u from eq. (3). Let's introduce the dimensionless variable $A=K / \beta$.u. Note that, from the definitions of $A$ and $\beta, A$ is proportional to the solubility of the element in sodium, so that it may be regarded as a solubility parameter. Then assuming the concentration of the nuclide in the sodium to be zero, Polley and Skyrme showed that release is super-stoichiometric if $A>1$ and sub-stoichiometric if $A<1$, in both cases becoming stoichiometric at long periods of time $\left(u^{2} . t / 4 D>>1\right)$ and if the radioactive period of the radionuclide is sufficiently long $\left(\mathrm{u}^{2} / 4 . \lambda . \mathrm{D}>>1\right)$. Thus stoichiometric release is favored when diffusion is slow compared with bulk corrosion. Moreover, Polley and Skyrme showed that it is achieved more rapidly when the element is selectively leached $(\mathrm{A}>1)$.

Since D. (ðC/ðx $)_{\mathrm{x}=0} \approx(\mathrm{K} / \beta$-u).Ci [cf. eq. (6)], super-stoichiometric release is associated to a depletion of the element in the steel near the surface (positive concentration gradient). This behavior is observed in sodium loop experiments for highly soluble elements like nickel, chromium and manganese. On the contrary, sub-stoichiometric release is observed for less soluble elements like cobalt, and corresponds to an enrichment of this element at the steel surface.

Deposition of radioactive nuclides on out-of-flux surfaces.

Assuming the concentration in the bulk sodium $C^{\prime}$ to be finite and constant, Polley and Skyrme showed that deposition of radioactive nuclides on out-of-flux surfaces may be reduced to a set of simple expressions for limiting values of the relevant dimensionless parameters, for both bulk corrosion and bulk deposition cases. These asymptotic expressions depend on the parameters of the model: $K, D, \beta, u$, $\lambda$. Deposition is always proportional to $C^{\prime}$.

For values of the main parameters representative of the conditions in sodium loop experiments, long term ${ }^{54} \mathrm{Mn}$ surface contamination $\left(\mathrm{Bq} / \mathrm{m}^{2}\right)$ can be expressed as $\mathrm{I}=\beta$.D.C $/ \mathrm{u}$ on the surfaces undergoing bulk corrosion and $\mathrm{I}=\beta$. $\mathrm{u}_{\mathrm{d}} . \mathrm{C}^{\prime} / \lambda$ on the surfaces undergoing bulk deposition (where $\mathrm{u}_{\mathrm{d}}=-\mathrm{u}$ is the deposition velocity).

Since $\beta$ and $\mathrm{u}_{\mathrm{d}}$ increase when temperature decreases, ${ }^{54} \mathrm{Mn}$ surface contamination rises rapidly with reducing temperature on the cold surfaces. On hot surfaces undergoing corrosion, little can be said about temperature dependence without detailed knowledge of the parameters $\beta, D$ and $u$.

Regarding cobalt, surface contamination can be expressed as $\mathrm{I}=\mathrm{K}$.t. $\mathrm{C}^{\prime}$ on all surfaces (or $\mathrm{I}=\mathrm{K}$.C' $/ \lambda$ ) at longer times: $\lambda . t>1$ ). Thus cobalt contamination is expected to depend on sodium velocity (if $\mathrm{k}<<\mathrm{k}_{\mathrm{a}}$ ) but little on temperature. 
Observed differences between ${ }^{54} \mathrm{Mn}$ and ${ }^{60} \mathrm{Co}$ or ${ }^{58} \mathrm{Co}$ deposition behaviors are primarily due to differences between manganese and cobalt solubility parameters A.

\section{IMPLEMENTATION OF THE MODEL}

The OSCAR code package

In the OSCAR modeling (initially developed for PWR [1]), fluid systems are discretized into as many volumes or regions as necessary. These regions are defined by geometric, thermohydraulic, neutron flux, material property, and operating characteristics. Several media are defined, as for example "fluid" and "deposit", and mechanisms are considered, which generate mass transfers between these media. Besides, the OSCAR code considers the convection, which transports species throughout the primary circuit, and the purification, which removes species from the circuit with a given efficiency when they go through the filters (or the traps) of the purification circuit. Moreover, the nuclides are described within filiation chains, taking into account radioactive decay constant and capture cross section if necessary.

Finally, for each medium, for each control volume and for each isotope considered, a mass balance is calculated.

Thus a new code OSCAR-Na which integrates the solution/precipitation model described in preceding section was recently developed in order to calculate the corrosion and the contamination in SFR. The only needed media in OSCAR-Na are "steel" and "sodium".

\section{The OSCAR-Na code}

The mass transfer between steel and sodium is given by eq. (4): $\Phi=K .\left(C_{i} / \beta-C^{\prime}\right)$. The surface concentration $C_{i}$ in the steel and the bulk sodium concentration $C^{\prime}$ need to be determined for each region and for each nuclide. This is done through two steps in the OSCAR-Na code:

Given $C^{\prime}, C_{i}$ is calculated by solving the general diffusion equation (5) with the boundary condition at the interface (6). The retained method for solving the diffusion equation is numerical. For this purpose, the metal is discretized in several layers covering the diffusion depth, which mainly depends on the interfacial velocity $\mathrm{u}$ and the diffusion coefficient in the steel $\mathrm{D}$. Thus the metal discretization may be different for each region and for each element. Thanks to the numerical method, the concentration profile in the steel can be calculated, even if the sodium concentration or the model parameters are time dependent. Moreover nuclide concentration profiles are taken into account for calculating the production rate of their descendant by neutron activation.

- Given $\mathrm{C}_{\mathrm{i}}$ in each region, $\mathrm{C}^{\prime}$ is calculated through a complete mass balance around the circuit involving all the elements, and taking into account convection, purification, radioactive decay, neutron activation and mass transfer (4) due to the solution/precipitation model.

Then iterations between both steps (numerical method for solving the diffusion equation for each region and complete mass balance around the circuit) are implemented for each time step, until convergence is reached for $C_{i}$ and $C^{\prime}$, for each nuclide and each region. The mass transfer between metal and sodium, as well as concentration in the sodium and concentration profile in the steel, are then calculated at all positions in the circuit as a function of time.

The OSCAR-Na code can be compared with the PSYCHE code (lizawa et al.[3] Erreur ! Source du renvoi introuvable.), a Japanese mass transfer code for corrosion product behavior in primary circuits of SFR reactors, implementing the same solution/precipitation model. In PSYCHE, the diffusion equation is analytically solved for each region and a simple mass balance in the sodium is calculated, using the mass conservation law along the circuit and taking into account release or deposition in each region in the system. This mass balance concerns only the radioactive contaminants ${ }^{54} \mathrm{Mn}$ and ${ }^{60} \mathrm{Co}$ in 
PSYCHE when the main elements of interest (and not only radio isotopes) are considered in OSCAR$\mathrm{Na}$.

\section{DETERMINATION OF THE MODEL PARAMETERS}

In this section, the key parameters $(\mathrm{u}, \mathrm{K}, \mathrm{D}$ and $\beta)$ of the solution/precipitation model are evaluated in order to calculate the contamination of the French SFR reactor PHENIX (see section 5). The parameters retained for OSCAR-Na are compared with the parameters used in the PSYCHE code [3] Erreur ! Source du renvoi introuvable..

Interfacial velocity

The interfacial velocity is the moving rate of the sodium/steel interface, due to corrosion and deposition. It may be defined as the difference between corrosion rate and deposition rate: $\mathrm{u}=\mathrm{u}_{\mathrm{c}}-\mathrm{u}_{\mathrm{d}}$.

\section{Corrosion rate}

The corrosion rate $u_{c}$ is the surface recession rate due to the corrosion of the steel. It can be related to the behavior of iron, as it is the major constituent of steel. In OSCAR-Na, the assumption is made that iron does not diffuse in steel. Consequently the iron profile in the steel is uniform and the iron release is stoichiometric: $\Phi_{\mathrm{Fe}}=\mathrm{C}_{\mathrm{Fe}} \cdot \mathrm{u}_{\mathrm{c}}$. [see eq. (3)].

Following eq. (4): $\Phi_{\mathrm{Fe}}=\mathrm{K}_{\mathrm{Fe}} \cdot\left(\mathrm{C}^{,{ }^{\mathrm{eq}}} \mathrm{Fe}^{-} \mathrm{C}_{\mathrm{Fe}}^{\prime}\right)$, where $\mathrm{C}^{, \mathrm{eq}}{ }_{\mathrm{Fe}}=\mathrm{C}_{\mathrm{Fe}} / \beta_{\mathrm{Fe}}$ is the iron equilibrium concentration in sodium.

We obtain the following expression for the corrosion rate:

$u_{c}=\frac{K_{F e}}{\beta_{F e}} \cdot\left(1-\frac{\mathrm{C}_{\mathrm{Fe}}^{\prime}}{C_{F e}^{\prime e ́ q}}\right)$ when $C_{F e}^{\prime}<C_{F e}^{\prime e ́ q}$ and $u_{c}=0$ when $C_{F e}^{\prime}>C_{F e}^{\prime e ́ q}$

This is in agreement with the fact that steel corrosion is governed by iron solution [4], i.e. is limited by the iron concentration in sodium.

$\mathrm{k}_{\mathrm{Fe}}$ can be deduced from experimental results. Indeed, from sodium loop experiment results obtained for temperatures representative of SFR primary circuit and for oxygen concentrations between 0.5 and $2.5 \mathrm{ppm}$, Brissonneau [5] proposes a mass loss equation that separates the contributions of general corrosion and preferential leaching. The general corrosion term corresponds to the following expression for the experimental corrosion rate:

$\mathrm{u}_{\text {cor }}=\mathrm{A}_{\text {cor }} \cdot[\mathrm{O}] \cdot \mathrm{e}^{\frac{-\mathrm{E}_{\mathrm{cor}}}{\mathfrak{R} \cdot \mathrm{T}}}$

Where $[\mathrm{O}]$ is the oxygen concentration in ppm, $\mathrm{A}_{\text {cor }}$ is a pre-exponential factor expressing a velocity, and $\mathrm{E}_{\mathrm{cor}}$ is the activation energy. This is consistent with the fact that corrosion of steels is controlled by a surface reaction involving oxygen, which acts as a catalyst [4] .

In sodium loop experiments investigated in [5], iron concentration in sodium was considered to be far from equilibrium concentration, so that from eqs. (7) and (8) : $\mathrm{K}_{\mathrm{Fe}}=\beta_{\mathrm{Fe}} \mathrm{u}_{\mathrm{cor}}$.

Moreover, corrosion of steels in sodium is known to increase with sodium velocity only up to a critical velocity, above which the corrosion can be considered as independent of velocity [4] Erreur !

Source du renvoi introuvable.. Above critical sodium velocity, the surface reaction limits the corrosion process. Since the surface reaction rate is very low for the considered oxygen concentration, it is likely that it effectively limits the iron release in the experiments considered in [5] Erreur ! Source du renvoi introuvable.. Then in these conditions: $\mathrm{K}_{\mathrm{Fe}}=\mathrm{k}_{\mathrm{Fe}}^{\mathrm{a}}=\beta_{\mathrm{Fe}} \mathrm{u}_{\mathrm{cor}}$.

This allows us to establish, from eq. (7) and the definition of $\mathrm{K}$, the general expression for $\mathrm{u}_{\mathrm{c}}$ used in OSCAR-Na: 
$\mathrm{u}_{\mathrm{c}}=\mathrm{u}_{\mathrm{cor}} \cdot \frac{\mathrm{k}_{\mathrm{Fe}}}{\mathrm{k}_{\mathrm{Fe}}+\beta_{\mathrm{Fe}} \cdot \mathrm{u}_{\mathrm{cor}}} \cdot\left(1-\frac{\mathrm{C}_{\mathrm{Fe}}^{\prime}}{\mathrm{C}_{\mathrm{Fe}}^{\prime \text { eq }}}\right)$ when $\mathrm{C}_{\mathrm{Fe}}^{\prime}<\mathrm{C}_{\mathrm{Fe}}^{\mathrm{é}}$

Brissonneau [5] gives the following values for the $u_{\text {cor }}$ parameters (8) which will be used in the OSCAR-Na code: $A_{c o r}=1.4310^{-8} \mathrm{~m} / \mathrm{s}, E_{c o r}=92500 \mathrm{~J} / \mathrm{mol}$. These values hold for oxygen content in the sodium lower than $5 \mathrm{ppm}$. It was obtained from low oxygen content experiments of Brehm [6].

Unlike in PSYCHE, no downstream factor [3, 5] is taken into account in this first version of OSCAR-Na. It is considered that the downstream effect (lower corrosion rate at the downstream positions of isothermal sections) can be reproduced by the code, as Fe concentration build up in Na can induce a saturation effect [7]. If it should not be confirmed by qualification of the code on loop experiments, some additional physics should be implemented in the code (role of particles etc.[4]).

Deposition rate

The deposition rate $\mathrm{u}_{\mathrm{d}}$ is the surface procession rate due to the deposition of stable and active corrosion products. It is defined in OSCAR-Na from the deposition flux for the different nuclides:

$u_{\mathrm{d}}=-\sum_{\mathrm{k}} \frac{\Phi_{\mathrm{k}}}{\rho_{\text {steel }}}\left(\right.$ if $\left.\Phi_{k}<0\right)$

Where $\rho_{\text {steel }}$ is the steel density. This definition needs all the major elements present in the steel to be calculated.

With eqs. (9) and (10) as definitions of $u_{c}$ and $u_{d}$, the interfacial velocity $u=u_{c}-u_{d}$ is calculated by the OSCAR-Na code, thanks to the numerical method for solving the diffusion equation and to the complete mass balance in the sodium. It is closely related to the iron behavior, i.e. its equilibrium concentration, characterized by the $\beta_{\mathrm{Fe}}$ coefficient (see section 4.4) and its surface reaction rate, assessed through sodium loop experimental results [see eq. (8)].

In the PSYCHE code, $\mathrm{u}_{\mathrm{c}}$ and $\mathrm{u}_{\mathrm{d}}$ are input data, obtained from the analysis of sodium loop experiment results. Each region has to be preselected as bulk corrosion type or bulk deposition type.

Effective mass transfer coefficient

The determination of the effective mass transfer coefficient $\mathrm{K}=\mathrm{k} \cdot \mathrm{k}_{\mathrm{a}} /\left(\mathrm{k}+\mathrm{k}_{\mathrm{a}}\right)$ needs to assess $\mathrm{k}$ and $\mathrm{k}_{\mathrm{a}}$.

In the OSCAR-Na code, the mass transfer coefficient $\mathrm{k}$ through the boundary layer in the flowing sodium is calculated from the following equation [8] Erreur ! Source du renvoi introuvable.:

$$
\mathrm{k}=0,023 \cdot \mathrm{Re}^{0,8} \cdot \mathrm{Sc}^{1 / 3} \cdot \frac{\mathrm{D}^{\mathrm{Na}}}{\mathrm{d}_{\mathrm{h}}}
$$

Where Re and Sc represent the Reynolds and Schmidt numbers, respectively, $\mathrm{D}^{\mathrm{Na}}$ is the diffusivity of the element in liquid sodium and $\mathrm{d}_{\mathrm{h}}$ the equivalent hydrodynamic diameter of the flow path. $\mathrm{D}^{\mathrm{Na}}$ is obtained for the different elements from the Sutherland-Einstein relation [9] Erreur ! Source du renvoi introuvable.:

$$
\mathrm{D}^{\mathrm{Na}}=\frac{\mathrm{k}_{\mathrm{B}} \cdot \mathrm{T}}{4 \cdot \pi \cdot \mu_{\mathrm{Na}} \cdot \mathrm{r}}
$$

Where $\mathrm{k}_{\mathrm{B}}$ is the Boltzmann constant, $\mathrm{T}$ the Kelvin temperature, $\mu_{\mathrm{Na}}$ the dynamic viscosity of sodium at temperature T, and $r$ the atomic radius of the element. In PSYCHE, the same eq. (11) is used for $\mathrm{k}$, but $\mathrm{D}_{\mathrm{Na}}$ is obtained from experimental results. The same $\mathrm{D}_{\mathrm{Na}}$ values are used for all the elements of interest. These values are compared in fig. 1 with the values calculated for OSCAR-Na from eq. (12). 
The surface reaction rate $\mathrm{k}_{\mathrm{a}}$ for iron is deduced from corrosion measurements: $\mathrm{k}_{\mathrm{aFe}}=\beta_{\mathrm{Fe}} \mathrm{u}_{\mathrm{cor}}$ (see preceding section). For other elements than iron, it is considered in OSCAR-Na that the surface reaction rate is much greater than the diffusion rate through the sodium boundary layer, and then has no effect on the mass flux: $\mathrm{K}=\mathrm{k}$ (local chemical equilibrium is obtained at the steel/sodium interface for these elements). This is at least valid for nickel, as it was reported that "the corrosion of nickel based alloys increases continuously with velocity to approximately the first power" [4], which shows that no release limitation by a surface reaction exists for nickel. Concerning deposition $673-693 \mathrm{~K}\left(400-420^{\circ} \mathrm{C}\right)$, a strong velocity effect was found except for iron corroded from stainless steel [10]. This in contradiction with the results of the AMTL-I loop for ${ }^{54} \mathrm{Mn}$ deposition, which are used by PSYCHE [3]. As a consequence, an experimental value of the surface reaction rate $k_{a}$ is taken into account for manganese in this code.

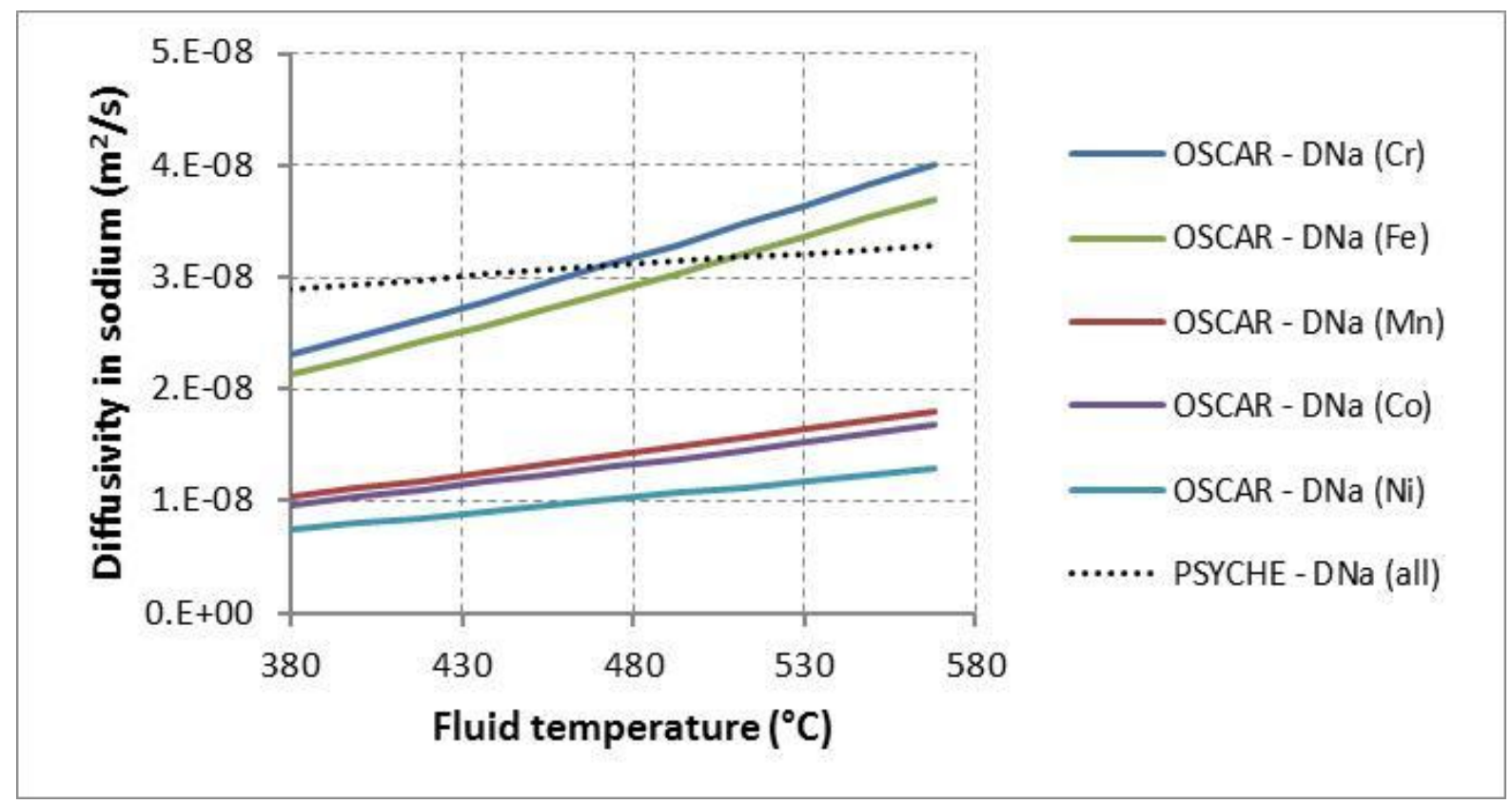

FIG. 1. Diffusivity in sodium used in OSCAR-Na and PSYCHE codes.

Steel diffusion coefficient

In this first version of OSCAR-Na, diffusion in the steel is characterized by a single diffusion coefficient $D$ independent of depth (ie steel composition), even if the diffusion may be enhanced in the ferrite layer which forms near the steel surface due to the nickel depletion [4]. This effective diffusion coefficient should incorporate lattice and grain boundary diffusion.

Moreover, as investigated by Brissonneau [5], diffusion enhancement due to the defects in the lattice produced by irradiation must be taken into account. Steady state values of the defect (vacancies and interstitials) concentrations were calculated according to Sizmann's analysis [11], and then the coefficient of diffusion, from the individual diffusion coefficient of the defects. As the defect concentration and then the diffusion coefficient vary as the square root of the neutron flux, the following equation is used for the determination of $D$ :

$\mathrm{D}=\mathrm{D}_{\mathrm{NP}}^{\mathrm{irr}} \cdot \sqrt{\mathrm{P}_{\mathrm{loc}}}+\mathrm{D}^{\mathrm{eq}}$

Where $\mathrm{D}^{\mathrm{irr}}{ }_{\mathrm{NP}}$ is the diffusion coefficient under irradiation at the nominal power of the reactor, $\mathrm{P}_{\text {loc }}$ is the local power fraction, and $\mathrm{D}^{\mathrm{eq}}$ is the diffusion coefficient at equilibrium (out of neutron flux). In OSCAR$\mathrm{Na}$, the same values of $\mathrm{D}_{\mathrm{NP}}^{\mathrm{irr}}$ are considered for all elements, and correspond to the diffusion under 
irradiation of iron in stainless steel, given in [5] Erreur ! Source du renvoi introuvable.. A literature review provides the $\mathrm{D}^{\mathrm{eq}}$ values for the different elements handled in the code: $\mathrm{Mn}$ [12], $\mathrm{Cr}$ [13], Ni [14] and Co [15]. Note that the values retained in this first version of OSCAR-Na correspond to the lattice diffusion and do not include the grain boundary diffusion. As the lattice diffusion is greatly increased under irradiation, neglecting grain boundary diffusion should not have a strong effect on the behavior of diffusion coefficient in the pin material. As most of the release comes from the pin, this assumption has only small consequences on the modelling of the total release. However, this might have a strong influence on the penetration depth of the deposited elements in the out-of-flux components (especially IHX).

In the future version of OSCAR-Na, the diffusion coefficient will change as a function of $\mathrm{Ni}, \mathrm{Mn}$ concentrations, using a Schaeffler like relation for ferrite stability in Ni-Cr-Mn steels, to take into account the diffusion enhancement in the ferrite surface layer (in or out of flux).

The retained values of the diffusion coefficients for OSCAR-Na (under irradiation and at equilibrium) as well as those used in the PSYCHE code are shown in fig. 2. The impact of irradiation is not taken into account in the PSYCHE code. It can be observed that PSYCHE values are close to OSCAR-Na values under irradiation, and much greater than OSCAR-Na values out of neutron flux. This might be due to the fact that, in PSYCHE, the diffusion coefficient is obtained from sodium loop release experiments [3]. Brehm et al. [6] suggested that, at the vicinity of the surface of a stainless steel exposed to sodium at high temperature, the strong release of soluble elements (especially chromium and nickel) creates high local concentration of vacancies that might enhance the diffusion (as under irradiation). It then might explain the close values of the diffusion coefficients under irradiation in OSCAR-Na and out-of-flux in PSYCHE.

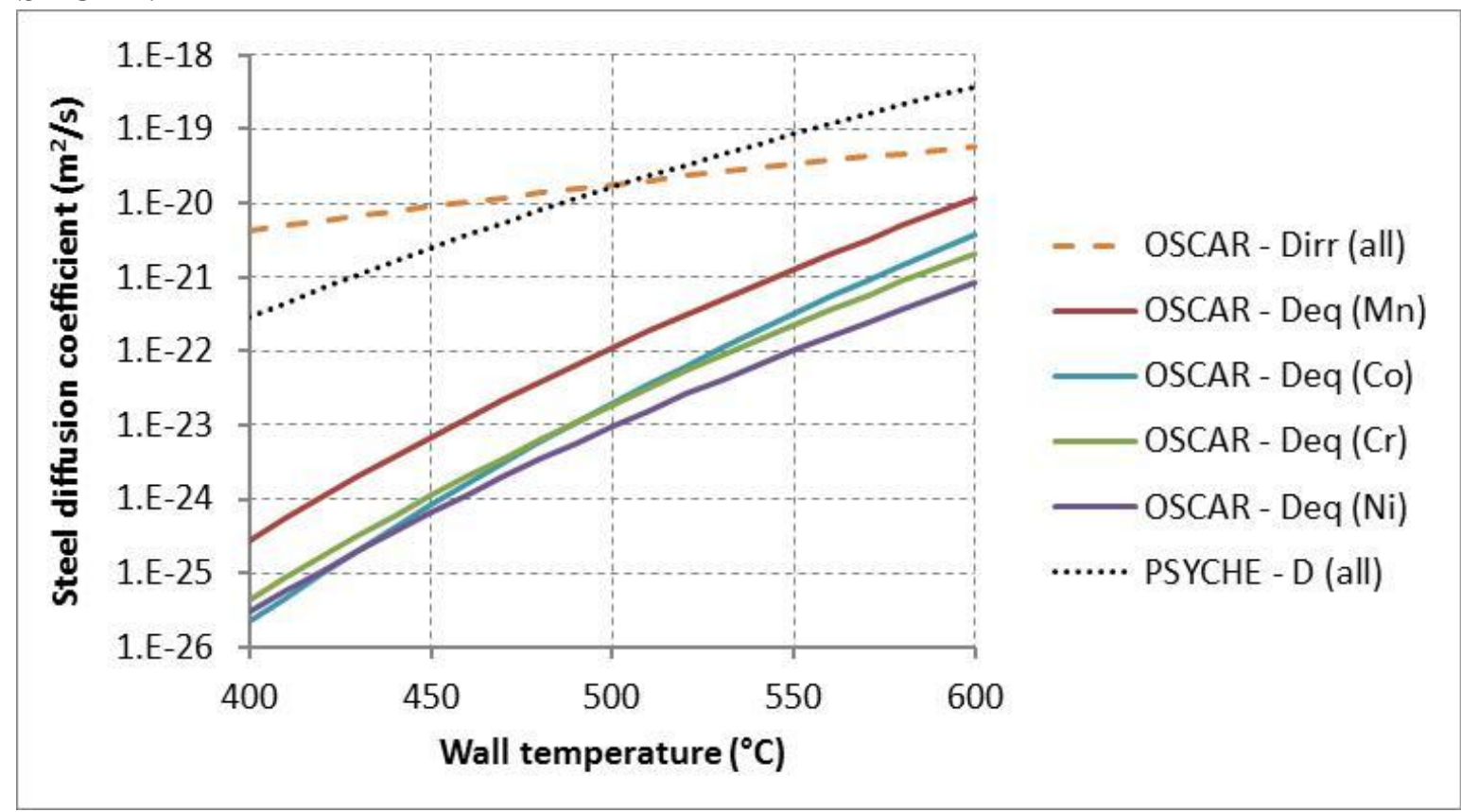

FIG. 2. Diffusivity in steel used in OSCAR-Na and PSYCHE codes.

Chemical partition coefficient

The chemical partition coefficient $\beta$ is probably the model parameter which is the most difficult to assess. Unfortunately, even if solubility of each pure metal in sodium has been measured, it was highlighted by several authors that using the classically accepted saturation for iron in a corrosion model 
would lead to corrosion rates order of magnitudes higher than what is observed in the experimental loops $[2,4,16]$.

From analysis of sodium loop data at $877 \mathrm{~K}\left(604^{\circ} \mathrm{C}\right)$ [6], Polley and Skyrme [2] evaluate the following values: $\beta<10^{9}$ for manganese and $\beta \sim 10^{11}$ for cobalt. lizawa et al. [3] also obtained an assessment of $\beta$ for manganese and cobalt by fitting the solution/precipitation model calculation to the activity profiles along a non-isothermal loop system, all the other model parameters having being assessed separately from experimental results. These values, used in the PSYCHE code, are shown in fig. 3. Note that oxygen concentration is considered to have an effect on $\beta$ for cobalt in the PSYCHE code. The plotted values of $\beta_{\mathrm{Co}}$ on fig. 3 are for $1 \mathrm{ppm}$ oxygen concentration.

In the OSCAR-Na code, values close to those cited above were first chosen (see fig. 3). But as the driving force for mass transfer is the difference of solubility of the steel constituents in the hot and the cold parts of the reactor [4], a greater temperature dependence than in PSYCHE is retained and is based on the temperature dependence of pure iron solubility in sodium, as reported in the experiments collected in [4]. Indeed, a too low temperature dependence of $\beta$ does not allow the iron precipitation in the cold parts of the system. In this first version of OSCAR-Na, same values of $\beta$ are retained for Fe, $\mathrm{Mn}, \mathrm{Cr}$ and $\mathrm{Ni}$, though it is known that $\mathrm{Mn}$ and $\mathrm{Ni}$ exhibit higher solubilities than $\mathrm{Fe}$ [4]. $\beta$ value for Co is roughly a factor 100 higher, accounting for the less soluble trend of cobalt.

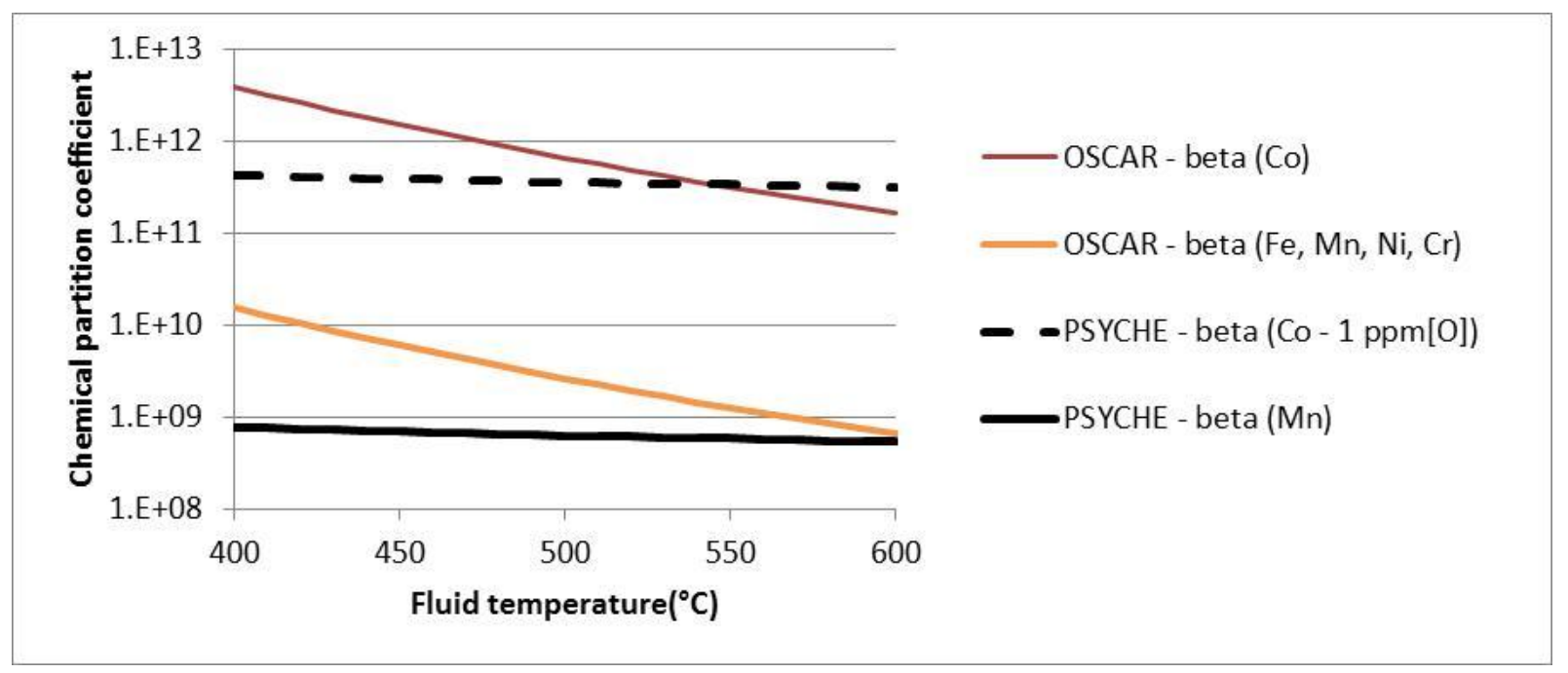

FIG. 3. Chemical partition coefficient in OSCAR-Na (first version) and PSYCHE codes.

More recent considerations come to a revision of the iron saturation to an even lower value in the last version of OSCAR-Na. An analysis of the limitation of the corrosion rate with sodium velocity in experimental loop was performed. Indeed, it was experimentally observed that stainless steel corrosion increases with sodium velocity, up to a critical value of about $4 \mathrm{~m} \cdot \mathrm{s}^{-1}$ at $923 \mathrm{~K} 650^{\circ} \mathrm{C}$, and then becomes roughly independent of it. The transition corresponds to $\mathrm{k}_{\mathrm{Fe}}=\mathrm{k}_{\mathrm{aFe}}$, when the transfer at the interface and in the boundary layer have similar values. Using classical value for $\mathrm{k}_{\mathrm{Fe}}$ (see Fig 1), typical loop configuration ( $R e$ and $d_{h}$ in Eq.11) and experimental values for $\mathrm{u}_{\text {cor }}$, it comes easily from the relation $\mathrm{k}_{\mathrm{Fe}}=\mathrm{k}_{\mathrm{aFe}}=\beta_{\mathrm{Fe}} \mathrm{u}_{\mathrm{cor}}$, that a critical sodium velocity of $4 \mathrm{~m} . \mathrm{s}^{-1}$ requires that $\beta_{\mathrm{Fe}}$ is again 50 times lower than the one proposed in Fig 3. Then the saturation for Fe is close to the one determined by Fleitman et al. (see ref. [4]), which has been selected by many authors for the codes, though it is not consistent with most of the experimental results. This is now the current value used in OSCAR-Na. 
Results obtained with the OSCAR-Na code

The French SFR reactor PHENIX has been simulated with this first version (V1.3) of the OSCAR-Na code, including parameters described above. For this calculation, a simple discretization of the primary system has been used. The temperature variation along the primary system is supposed to be correctly represented with 10 regions for IHX and 15 regions for the core. Core region temperatures correspond to those of an average assembly. The actual temperature gradient in a location selected as a region is lower than $20 \mathrm{~K}$. This allows for correct average values for the most temperature dependent relationships (Eq.8 in particular).

Other characteristics used for this calculation are as follows. Stainless steel is the material used for the cladding and the IHX. Five elements are taken into account: $\mathrm{Fe}, \mathrm{Mn}, \mathrm{Ni}, \mathrm{Cr}$ and $\mathrm{Co}$, including the filiation chains. The oxygen concentration is $1 \mathrm{ppm}$, which corresponds to a cold trap temperature of $393 \mathrm{~K}\left(120^{\circ} \mathrm{C}\right)$, as usually fixed as operating condition in PHENIX. The purification rate in cold traps corresponds to $0.14 \%$ of the primary flow rate. The simulation covers 1750 days at nominal power. In these conditions, the corresponding calculation time is roughly half-an-hour.

The calculated IHX surface contamination (i.e. surface activity) is shown in fig. 4 for ${ }^{54} \mathrm{Mn}$, ${ }^{60} \mathrm{Co}$ and ${ }^{58} \mathrm{Co}$. The global amount of contamination as well as the contamination profiles and their relative position for the 3 radionuclides are consistent with the measurements performed on PHENIX IHX. Moreover, the profiles are in agreement with those expected from the analysis of Polley and Skyrme model (see related section). The surface activity $\left(\mathrm{Bq} / \mathrm{m}^{2}\right)$ is close to the following asymptotic expressions:

- $\mathrm{I} \approx \beta \cdot \frac{\mathrm{D}}{\mathrm{u}} \cdot \mathrm{C}^{\prime}$ for ${ }^{54} \mathrm{Mn}$ on surfaces undergoing bulk corrosion (dependence on temperature is undefined).

- $\mathrm{I} \approx \beta \cdot \frac{\mathrm{u}_{\mathrm{d}}}{\lambda} \cdot \mathrm{C}^{\prime}$ for ${ }^{54} \mathrm{Mn}$ on surfaces undergoing bulk deposition (contamination rises rapidly with reducing temperature).

- $\mathrm{I} \approx \frac{\mathrm{K}}{\lambda} \cdot \mathrm{C}^{\prime}$ for ${ }^{58} \mathrm{Co}$ and ${ }^{60} \mathrm{Co}$ on all surfaces (little dependence on temperature).

In particular, from the ${ }^{54} \mathrm{Mn}$ profile, the transition temperature between the bulk corrosion zone and the bulk deposition zone can be assessed at around $753 \mathrm{~K}\left(480{ }^{\circ} \mathrm{C}\right)$. This is in agreement with the transition temperature observed by Ukai on JOYO pins [17] and Furukawa on long term mass transfer experiments[18].

The release calculation is also consistent with the known preferential leaching of manganese and retention of cobalt, associated with reduced or increased concentration at the steel surface, respectively (see the analysis of P\&S model). This difference in calculated results for manganese and cobalt is induced by the $\beta$ coefficient retained in OSCAR-Na for both elements.

The calculated interfacial velocity $u$ is shown in fig. 5 (lower full line), as well as the experimental corrosion rate $\mathrm{u}_{\mathrm{cor}}$ obtained from loop experiments with low iron concentration in sodium (upper full line). The difference between $u$ and $\mathrm{u}_{\mathrm{cor}}$ is related to the calculated iron concentration in the sodium. Moreover, this graph shows the transition temperature of $753 \mathrm{~K}\left(480{ }^{\circ} \mathrm{C}\right)$ calculated with OSCAR-Na. This means that bulk corrosion takes place from the upper middle part of the core to the upper middle part of the IHX and that deposition occurs in the lower parts of the core and the IHX.

The corrosion rate $u_{c}$ and deposition rate $u_{d}$ used in the PSYCHE code [3] [3] are also presented in fig. 5 (as PSYCHE defines hot and cold zone, there is a step transition in the $u$ value that is not observed for OSCAR-Na). This shows that interfacial velocity calculated with OSCAR-Na is consistent with values used in PSYCHE. 

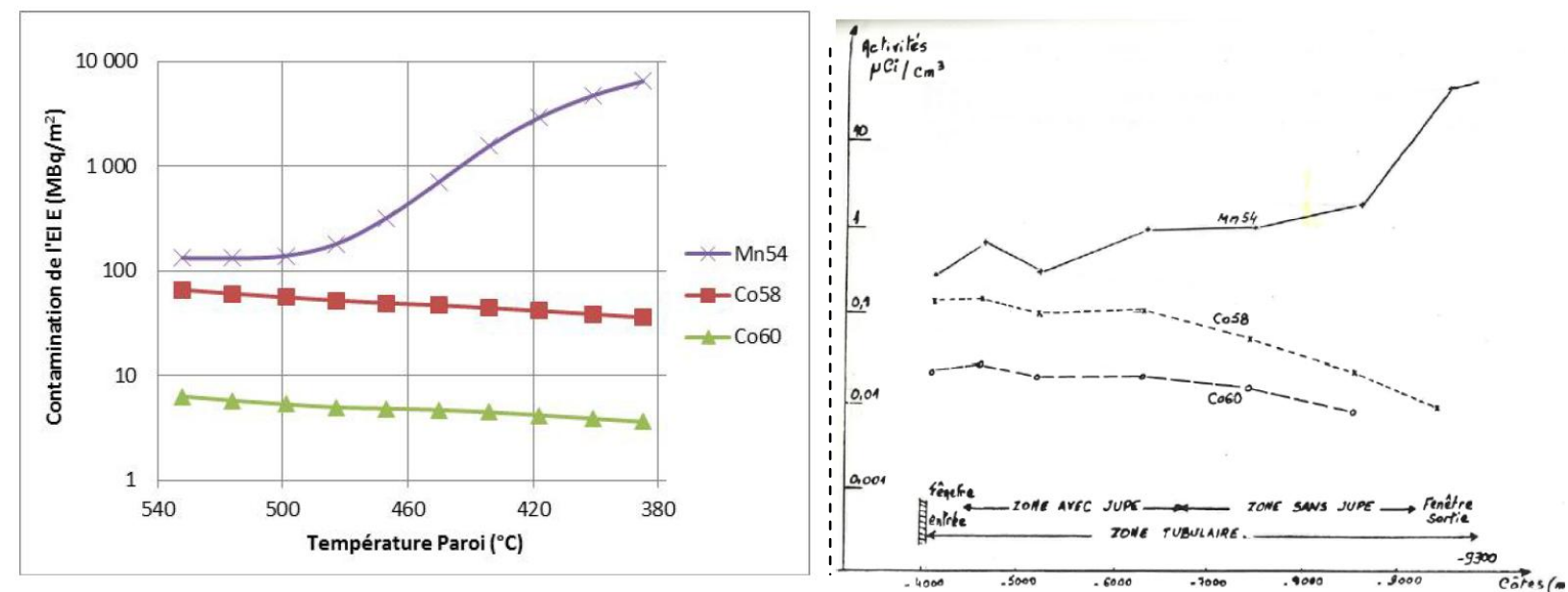

FIG. 4. IHX contamination calculated by OSCAR-Na (left) and measurement (right) for PHENIX reactor.

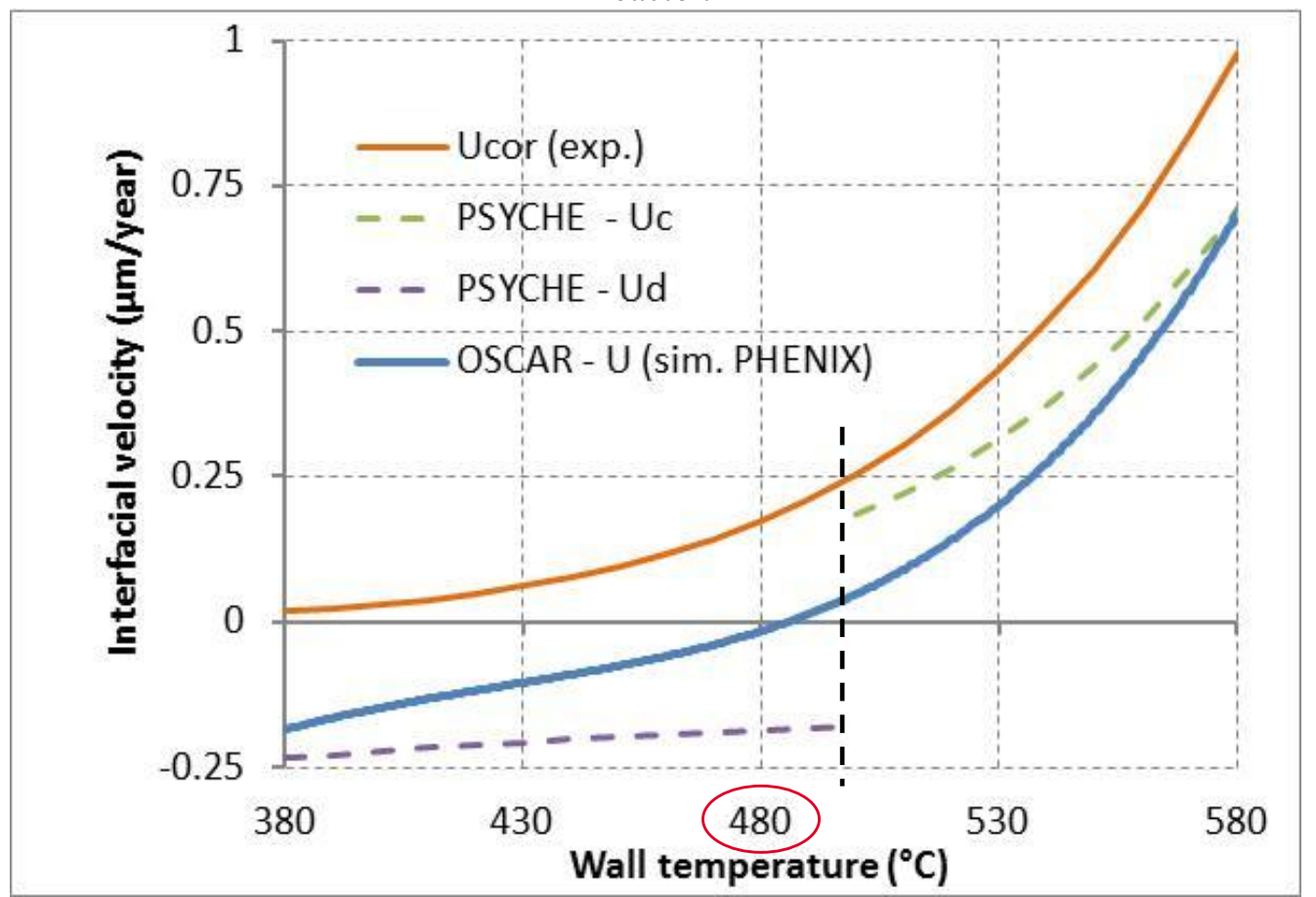

FIG. 5. Interfacial velocity in OSCAR-Na and PSYCHE.

The following additional information can be deduced from this simulation for a PHENIX like reactor: i) IHX undergoes bulk corrosion at its hotter part and a non-negligible amount of the deposition occurs in the lower part of the core ; ii) $\mathrm{IHX}^{54} \mathrm{Mn}$ contamination is expected to increase in cold regions (undergoing bulk deposition) and decrease in hot regions (undergoing bulk corrosion) if the corrosion rate increases (due to an increase of oxygen concentration for example). It is also expected to increase in hot regions with diffusion coefficient $D^{e q}$, but not in cold regions; iii) IHX cobalt contamination is expected to increase with the sodium velocity; iv) super-stoichiometric trend for ${ }^{54} \mathrm{Mn}$ release and substoichiometric trend for ${ }^{58} \mathrm{Co}$ and ${ }^{60} \mathrm{Co}$ release are enhanced by the diffusion coefficient under irradiation. ${ }^{60} \mathrm{Co}$.

Some discrepancies still exist, as the higher calculated release for ${ }^{58} \mathrm{Co}$ as compared to the one for 


\section{CONCLUSION}

A solution/precipitation model has been implemented in the OSCAR-Na code to simulate mass transfer of corrosion products and related contamination in the primary system of SFR reactors. Thanks to a numerical method used for solving the diffusion equation in steel and to a complete mass balance in the sodium, the interfacial velocity due to corrosion or deposition is calculated by the OSCAR-Na code for each surface of the primary system. It is mainly determined by the iron equilibrium concentration in the sodium and its oxygen enhanced solution rate. These parameters concerning iron as well as the other parameters of the model have been assessed from a literature review. In particular, enhancement of solid state diffusion due to irradiation is taken into account and the lowest iron saturation has to be selected.

Even with a simplified primary system description, simulation of the French SFR reactor PHENIX with the first version V1.3 of OSCAR-Na was able to assess the correct amount of contamination and the correct contamination profiles on IHX surfaces for ${ }^{54} \mathrm{Mn},{ }^{58} \mathrm{Co}$ and ${ }^{60} \mathrm{Co}$ radionuclides, compared with measurements. The analysis of the solution/precipitation model allows predicting the impact of the key parameters on the contamination of a PHENIX like reactor.

Further calculations are in progress on experimental loops in order to qualify the code. New PHENIX calculations will be undertaken with the finalized parameters and taking into account as much as possible the real operating conditions, aiming at full qualification of the OSCAR-Na code by comparison with the PHENIX contamination measurements. Further improvements of the models will also be considered, as the integration of the co-deposition (carbide, oxide or nitride formation), grain boundary diffusion, new release mechanisms at high oxygen contents... 


\section{References}

1. Génin, J.B. in the International Conference on Water Chemistry of Nuclear Reactors Systems. 2010. Quebec (Canada), 2010, pub: NPC.

2. Polley, M.V. and G. Skyrme, J. Nuc. Mat., 1978. 75(2): p. 226-237.

3. lizawa, K., et al. in Fission and corrosion product behaviour in Primary Circuit of LMFBRs, IWGFR/64. 1987. Karlsruhe, RFA, 5-8 May 1987, edited by H. Feuerstein and A.W. Thorley, pub: KfK 4279.

4. Weeks, J.R. and H.S. Isaacs, Advances in corrosion science and Technology, 1973. 3: p. 1-66.

5. Brissonneau, L., J. Nuc. Mat., 2012. 423(1-3): p. 67-78.

6. Brehm, W.F. and R.P. Anantatmula. in Material Behavior and Physical Chemistry in Liquid Metal Systems. 1982. Karlsruhe, 24-26 mars, 1981, edited by H.U. Borgstedt, pub: Plenum Press.

7. Zhang, J., T.F. Marcille, and R. Kapernick, Corrosion, 2008. 64(7): p. 563-573.

8. Treybal, R.E., Mass Transfer Operations. 1965, New York: Mc Graw-Hill.

9. Guminski, C. in Material Behavior and Physical Chemistry in Liquid Metal Systems 2. 1995. Karlsruhe, 2426 mars, 1993, edited by H.U. Borgstedt, pub: Plenum Press.

10. Claxton, K.T. and J.G. Collier, J. Brit. Nuc. En. Soc., 1973. 12(1): p. 63-75.

11. Sizmann, R., J. Nuc. Mat., 1978. 69\&70: p. 386-412.

12. Smith, A.F. and R. Hales, Met. Sci., 1975. 9: p. 181-184.

13. Perkins, R.A., R.A. Padgett, and N.K. Tunali,. Met. Trans., 1973. 4(11): p. 2535-2540.

14. Perkins, R.A., Met. Trans., 1973. 4(7): p. 1665-1669.

15. Patil, R.V., G.P. Tiwari, and B.D. Sharma,. Met. Sci., 1980. 14(11): p. 525-528.

16. Clement, C.F. and P. Hawtin. in International Conference on Liquid Metal Technology in Energy Production. 1976. Champion, Pennsylvania, 3-6 may 1976, edited by M.H. Cooper, pub: American Nuclear Society.

17. Ukai, S., et al., in Materials for nuclear reactor core application. 1987, BNES: London. p. 341-348.

18. Furukawa, T., S. Kato, and E. Yoshida, J. Nuc. Mat., 2009. 392(2): p. 249-254. 